\title{
Estimation of short-duration rainfall intensity from daily rainfall values in Klang Valley, Malaysia
}

\author{
Abdullah Al Mamun ${ }^{1}$ (D) Md. Noor bin Salleh ${ }^{1} \cdot$ Hanapi Mohamad Noor ${ }^{2}$
}

Received: 8 May 2018 / Accepted: 11 October 2018 / Published online: 19 October 2018

(c) The Author(s) 2018

\begin{abstract}
Data on intensity-duration-frequency or design rainfall are one of the most important information required for various hydrological and water resources studies. However, such crucial data are often unavailable in various parts of the world due to lack of enough rain gauging stations. It is not only tedious to determine design rainfall from the raw data but also occasionally impossible to calculate due to lack or absence of short-duration rainfall data. Generally, the manual rain gauges outnumber the automatic gauges, making it difficult to have adequate data on short-duration rainfall values, which is very important for urban hydrology. However, no graphical or mathematical relation could be found in the literature, which can be used for quick estimation of short-duration design rainfall from the daily rainfall data recorded by the manual stations. Annual maximum rainfall data from 143 rain gauging stations located at Klang Valley in Malaysia were used in this study. Statistical analyses and logarithmic graph fitting techniques were used to develop excellent correlation between short-duration rainfall and daily rainfall values for 96 automatic and 46 manual stations. Rainfall data analyze the design rainfall data of various duration and return periods. The 15,30 and $45 \mathrm{~min}$ of short-duration rainfall, which is the most common rainfall duration in the study area, was observed to be $32.4 \%, 47.1 \%$ and $57.4 \%$ of the daily rainfall amount, respectively. The amount of rainfall during 1-, 2- and 3-h storm events contribute $64.9 \%, 76.5 \%$ and $80.9 \%$ of the daily rainfall. Such relations can be used for quick estimation of short-duration rainfall resulting in saving time, money and other resources.
\end{abstract}

Keywords Annual maximum rainfall $\cdot$ Design rainfall $\cdot$ Global study $\cdot$ Short duration · Tropical climate

\section{Introduction}

Rainfall data are very important for climate study, water resources evaluation, drainage design (Desa and Rakhecha 2004; Wang 1987), environmental studies and many other purposes. As such, most of the countries try to avail as many rainfall and other climate monitoring stations as possible. Continuous collection and archiving of various types of climatic data including the rainfall are of enormous value to study the climate change effects on the environment and society. It is reported that rainfall of the last century is the highest over the past 8500 years (Hong et al. 2014). In a

Abdullah Al Mamun

mamun@iium.edu.my

1 Department of Civil Engineering, Kulliyyah of Engineering, International Islamic University Malaysia (IIUM), Jalan Gombak, 53100 Kuala Lumpur, Malaysia

2 Department of Irrigation and Drainage (DID), Ministry of Natural Resources and Environment, Putrajaya, Malaysia warming environment, the increasing trend of extreme rainfall events is seen, in terms of either rainfall quantity or event frequency (Goswami et al. 2006, Allan and Soden 2008). It is also evident that in some parts of the tropics, seasonality of rainfall is also changing (Kumar 2013). At least, the extreme rainfall events in Peninsular Malaysia are reported to show increasing trend between the years 1975 and 2010 (Syafrina et al. 2015). As such, the need for analyzing the available rainfall data has become very much crucial for good planning for water resources development (Okonkwo and Mbajiorgu 2010). Quantification of rainfall is needed for proper planning and designing of various water resource projects (El-Sayed 2011). However, estimating short-duration rainfall intensities is a paramount need in many water-related projects such as urban drainage design (Haddad et al. 2011) and to mitigate the flash floods in the hilly areas. Doing over-design or under-design of hydraulic structures such as farm dams or culverts may yield a considerable waste of national resources or may compromise the safety of the structures (Reich 1961, 1963) and people living downstream 
of the hydraulic structures. According to Hamzah (2005), using at-site data to estimate design rainfall is the most common and reliable practice. However, he recommended regional estimation (Hosking and Wallis 2005) to calculate design rainfall which he described as more precise method of estimation.

Desa and Rakhecha (2004) analyzed historical rainfall data (1971-1999) from 13 rain gauges in Selangor, Malaysia, and described the characteristics of short-duration extreme rainfall in the study area. The reported results can be helpful to design urban drainage system in Selangor. In this study, an attempt has been made to estimate short-duration rainfall intensity by correlating with the daily rainfall data of the Klang Valley. The specific objective of this paper was to develop equations and envelope curves to estimate short-duration (<24 h; e.g., 15, 30, 45 min, 1, 2, 3, 4, 5, 6, 9,12 and $18 \mathrm{~h}$ ) rainfall intensity by using rainfall data of various storm durations. It was anticipated that the availability of such design charts and equations would enable quick estimation of any short-duration rainfall for planning and design purpose.

\section{Literature review}

Rashid et al. (2012) have developed short-duration rainfall intensity-duration frequency empirical equations for Sylhet City Corporation (SCC), Bangladesh. To estimate the shortduration rainfall intensity (SDRI) from daily rainfall data, they used an empirical reduction formula given by Indian Meteorological Department (IMD) targeting at estimating rainfall intensity of any return period with the least amount of effort. The equation is as follows:

$P_{t}=P_{24}\left(\frac{t}{24}\right)^{(1 / 3)}$

where $P_{t}$ is the required rainfall depth in $\mathrm{mm}$ at $t$-h duration, $P_{24}$ is the daily rainfall in $\mathrm{mm}$ and $\mathrm{t}$ is the duration of rainfall for which the rainfall depth is required in hr. Using the same equation, Chowdhury et al. (2007) developed the short-duration intensity duration frequency (IDF) curve for SCC with return period of 2, 5, 10, 50 and 100 years. And also Logah et al. (2013) used the same equation to estimate short-duration rainfall. However, they actually developed short-duration intensity duration frequency curve for the Accra city, capital of Ghana. Nguyen et al. (1998) proposed a method for estimating the distribution of short-duration (e.g., $1 \mathrm{~h}$ ) extreme rainfalls at sites where data for the time interval of interest do not exist, but rainfall data for longer duration (e.g., 1 day) are available (partially gaged sites). The method was based on the scale invariance theory and the methodology was applied to extreme rainfall data from a network of
14 recording rain gauges in Quebec (Canada). They have shown that the rainfall estimate obtained by this method is comparable with those based on available at-site data. Garcia-Bartual and Schneider (2001) analyzed 408 rainfall events in Alicante (Spain) for the period of 1925-1992 and fitted nine frequently used empirical functions to estimate maximum expected short-duration rainfall intensities from extreme convective storms. They assessed the reliability of the functions and concluded that three parameter extreme value (such as generalized extreme value-GEV) distribution function provide satisfactory result.

The generalized least squares regression (GLSR) model to estimate design rainfall for short durations was presented by Haddad et al. (2011), which was applied for Australian data. They have drawn conclusions that the equations based on GLSR gave satisfactory outcomes for both 6-min and 1-h durations and their assumptions for the model also met the criterion. Therefore, recommendation was made to use the GLSR-based model which can give more consistent estimates of short-duration rainfall intensity. Yu et al. (2004) developed regional IDF formulas for non-recording sites based on the scaling theory by analyzing data from forty-six recording rain gauges over northern Taiwan. Their proposed formulae resulted in reasonable verifications and simulations. Smithers and Schulze (2001) used a regional approach based on L-moments to give estimation of shortduration $(\leq 24 \mathrm{~h})$ design storms in South Africa. The method used was aiming at eliminating data limitation problems and also to improve reliability. They performed regionalization by using geographical and hydrometeorological features of the sites. The paper provided ways to estimate shortduration design storms at the locations where no rain gauge is installed in South Africa. They showed that for a 24-h storm, the mean of daily annual maximum series (AMS) can be more or less precisely estimated as a function of mean annual precipitation (MAP).

The magnitude of overall rainfall as well as its annual variability and seasonal distribution has been severely altered due to the change in the climate (Min et al. 2011; Easterling et al. 2000; Zeng et al. 1999). Cheng and Agha Kouchak (2014) showed that for a changing climate the conventional IDF curves are not sufficient to design an infrastructure. Their calculation demonstrated that stationary assumptions of IDF curves can underestimate the extreme rainfall events by $60 \%$. However, they used Bayesian inference to estimate non-stationary IDF curves. Hamada et al. (2015) analyzed space-borne rainfall data of 11 years to conclude that there is little relationship between extreme convective events and extreme rainfall events. 


\section{Methodology}

\section{Study area}

The study area is about $8396 \mathrm{~km}^{2}$ and is located along the west coast of the Peninsular Malaysia. The valley is very strategic and important as the country's main economic, business and commercial hubs are located within the Klang Valley. It lies within latitude of about $2^{\circ} 40^{\prime} 49^{\prime \prime}$ to $3^{\circ} 50^{\prime} 28^{\prime \prime} \mathrm{N}$ and longitude of $102^{\circ} 09^{\prime} 31^{\prime \prime}$ to $100^{\circ} 43^{\prime} 32^{\prime \prime}$

E. East side of the study area is hilly (elevation varying from average value of about $80 \mathrm{~m}$ to as high as $600 \mathrm{~m}$ MSL). The average elevation at the main valley area varies within 20-35 m, MSL besides having patches of hilly areas within the valley itself. The terrain, eventually, slopes down to sea coast at the west side where the Straits of Malacca is located.

Similar to the other parts of the west coast of the Peninsula, the climate has more or less uniform temperature throughout the season (at night $24-27^{\circ} \mathrm{C}$ and at the day time $33-38{ }^{\circ} \mathrm{C}$ ), high humidity and heavy rainfall with two major monsoon seasons (southeast and northeast monsoon). The climate between the two monsoons is characterized by distinct transitional seasons that last about 3 months each. Although the east coastal areas of the Peninsula receives high rainfall during the months of November-January, most part of the Klang valley receives less rain during this northeast monsoon due to the blocking effect of the central mountain range running from north to south of the valley. The average annual rainfall of the project area may vary from 1800 to $2400 \mathrm{~mm}$, which will be verified upon collection of the rainfall data. This area is also covered by satisfactory number of rain gauging network, which is important for such study.

\section{Data availability}

According to the Department of Irrigation and Drainage (DID) database in 2015, there are 236 rainfall stations in the State of Selangor and 54 rainfall stations within the Federal Territory of Kuala Lumpur. However, 132 and 8 stations were selected from two states, respectively, as only these stations passed the quality check criteria (Einfalt et al. 2008, Mudenda 2007 and NOAA 2017). Three stations from the Malaysian Meteorological Department (MMD) were also included in this study, which made the total number of stations with acceptable rainfall data to be 143 . There were 96 automatic and 47 manual stations used in this study. The data period varied depending on the installation date of the rain gauge and also the quality of useable data for acceptable analysis. The oldest data were from 1927, while a few stations started operation in 2004. For all rainfall stations, the latest data were collected till the year 2013, when the study was conducted. The final numbers of usable years of data were determined after checking the quality of the annual maximum rainfall data.

\section{Data screening}

The annual maximum rainfall data of 15-, 30-, 45-min, 1-, 2-, 3-, 4-, 5-, 6-, 9-, 12- and 18-h durations were retrieved for the automatic stations. However, the DID's data bank provided the annual maximum series (AMS) rainfall of 24-h duration (daily rainfall) for the manual stations. Smithers (1993) showed that for AMS analysis with sufficient data, if inconsistent data are removed it does not make any significant difference in results with those data included. However, to achieve greater accuracy and high reliability of the results, the data and its collection procedures were screened for quality control using the standard protocols and methods used by Einfalt et al. (2008), Mudenda (2007) and NOAA (2017)

Some of the examples are identification of nearly impossible values, detection of gaps in the data, sensitivity of measurement variability, procedure of internal and spatial consistency. How the data are collected, screened and archived by the relevant authorities in Malaysia was also given due to considerations. The data were screened through scatter plots, and outlier ( 95 percentile $<$ data $<5$ percentile) analysis was conducted to discard the doubtful data, which amounted to be very negligible; about $0.018 \%$ of the total data. The historical rainfall data of the Department of Irrigation and Drainage Malaysia (DID) and MMD are stored in the database managed by TIDEDA program developed by National Institute of Water and Atmospheric Research (NIWA 2017), New Zealand. The number of usable quality data for various durations of rainfall ranged between 9 and 86 years.

\section{Statistical analyses}

Quartile analysis was conducted to prepare the box plots, which describes the variation and distribution of data within the time period considered for the analysis. The plot shows the maximum, minimum and three quartiles $(25,50$ and 75 percentiles). The mean or the median each has its own advantages and disadvantages. The median was preferred over the mean, as the former is not influenced by the exceptional AMS values.

\section{Regionalization}

A regional approach to rainfall frequency analysis attempts to supplement the limited information available

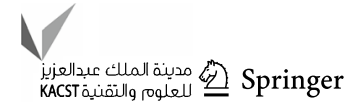


from the relatively short periods of record with regional information from surrounding stations (Smithers and Schulze 2000). The reality is that in nearly all the practical situations a regional method is proved to be more efficient than the application of an at-site analysis (Potter, 1987). This opinion is also backed by both Lettenmaier (1985) who urged that "regionalisation is the most appropriate method of improving flood quantile estimation," and Hosking and Wallis (2005) who, after a review of the recent literature, advocated the use of regional frequency analysis based on the belief that a "well conducted regional frequency analysis will yield quantile estimates accurate enough to be useful in many realistic applications." Rainfall data of various durations were plotted on the map to study the spatial distribution of the mean annual rainfall values and their ratios to the daily rainfall values. Data of the selected stations were plotted (using Grapher software) to obtain isohyetal maps to find out the similarity of rainfall pattern within the study area.

\section{Short-duration rainfall design charts}

Relation of short-duration rainfall with the daily rainfall value was determined and plotted to develop regression model. Depending on the nature of curvature and in order to get reliable estimates, two equations were proposed: one equation for the rainfall duration up to $2 \mathrm{~h}$ and the other one for duration more than $2 \mathrm{~h}$ but less than $24 \mathrm{~h}$ (1 day). There are possibilities of having slightly different estimated rainfall values for the transition duration which is $2 \mathrm{~h}$, in this particular study. As such, rainfall of any duration close to $2 \mathrm{~h}$ should be calculated using both equations and the higher value should be accepted for the design rainfall value. Short-duration rainfall data of the nearby automatic station were considered for testing the output design graphs.

\section{Results and discussion}

\section{Evaluation of available data}

Sufficient numbers of stations are available in the Klang Valley, and they are satisfactorily distributed within the study area. However, the scattered plots of the rainfall data indicated discrepancies in among a few number of stations. This could be due to faulty gauging stations or improper processing of raw data. Specially, data from the stations installed after the year 2000 could not be issued due to exceptionally high and low (both) values, which can be attributed to the incomplete calibration of the instruments until the time the data were collected. Nevertheless, as stated in the previous section, the outliers were identified and eliminated from the raw data to reduce the noise in the statistical analysis (Cunnane 1989).

\section{Statistical results}

Statistical summary of rainfall data from the selected automatic station in Klang Valley is given in Table 1. The highest daily maximum rainfall value was recorded at $156.4 \mathrm{~mm}$ and the lowest was $77.0 \mathrm{~mm}$. The difference between the highest and lowest daily rainfall value was almost double.

Box plots are very efficient ways to show the statistical distribution of data, indicating the maximum, 75 percentile, median, 25 percentile and minimum values, from the top of the graph, respectively. A small box with narrow gap between high and low values indicates good consistency and uniformity among the data. Box plot of the mean annual maximum values for the various durations of all rainfall stations in Klang valley is shown in Fig. 1.

The overall patterns of the percentile values look similar. However, the lower rainfall magnitude (closer to the 25 percentile) is not as variable as that of the higher rainfall values. Also, the 75-25 percentiles for shorter durations look

Table 1 Statistical summary of mean annual rainfall values in Klang Valley

\begin{tabular}{|c|c|c|c|c|c|c|c|c|c|c|c|c|c|}
\hline \multirow[t]{2}{*}{ Parameter } & \multicolumn{13}{|c|}{ Annual maximum rainfall $(\mathrm{mm})$ for the duration of } \\
\hline & $15 \min$ & $30 \mathrm{~min}$ & $45 \mathrm{~min}$ & $1 \mathrm{~h}$ & $2 \mathrm{~h}$ & $3 \mathrm{~h}$ & $4 \mathrm{~h}$ & $5 \mathrm{~h}$ & $6 \mathrm{~h}$ & $9 \mathrm{~h}$ & $12 \mathrm{~h}$ & $18 \mathrm{~h}$ & $24 \mathrm{~h}$ \\
\hline No. of stations & 140 & 139 & 140 & 140 & 140 & 140 & 140 & 140 & 140 & 137 & 141 & 138 & 143 \\
\hline Minimum & 21.3 & 32.7 & 39.6 & 46.4 & 54.7 & 55.9 & 57.1 & 58.4 & 59.5 & 63.3 & 64.8 & 65.0 & 77.0 \\
\hline 10 percentile & 27.5 & 43.5 & 52.7 & 60.7 & 71.9 & 74.1 & 75.7 & 77.9 & 79.6 & 80.6 & 81.5 & 84.5 & 91.3 \\
\hline Median & 33.3 & 50.6 & 61.3 & 68.7 & 80.4 & 87.5 & 90.6 & 93.1 & 94.0 & 97.5 & 99.2 & 102.6 & 107.8 \\
\hline Mean & 34.4 & 51.9 & 62.5 & 69.7 & 82.4 & 87.3 & 90.1 & 92.3 & 93.6 & 96.2 & 97.6 & 101.5 & 108.6 \\
\hline 90 percentile & 40.8 & 60.7 & 73.4 & 79.7 & 96.2 & 101.0 & 103.4 & 105.7 & 107.4 & 112.6 & 113.6 & 115.6 & 124.6 \\
\hline Maximum & 71.7 & 89.1 & 99.4 & 108.4 & 117.8 & 122.1 & 129.8 & 137.5 & 141.8 & 144.9 & 145.2 & 145.3 & 156.4 \\
\hline Skewness & 2.2 & 1.4 & 1.1 & 1.0 & 0.4 & 0.3 & 0.4 & 0.5 & 0.5 & 0.4 & 0.0 & 0.2 & 0.6 \\
\hline $\mathrm{SD}$ & 6.7 & 8.1 & 9.2 & 9.7 & 11.0 & 12.1 & 12.7 & 13.1 & 13.3 & 14.0 & 14.9 & 14.6 & 14.1 \\
\hline
\end{tabular}


Fig. 1 Box plot of the rainfall values of various durations

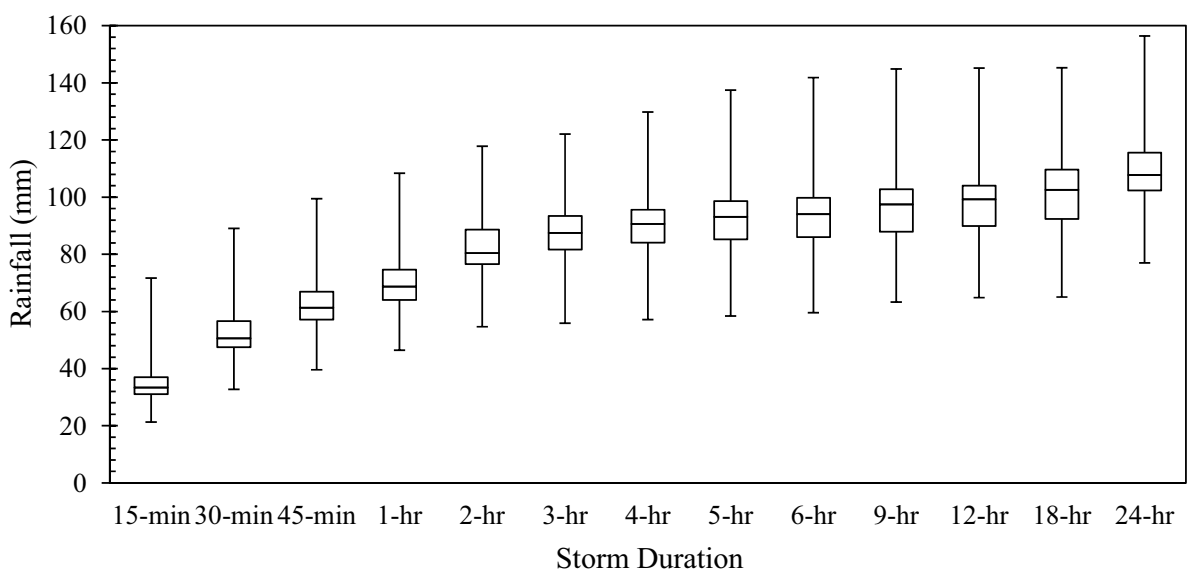

to have more uniform pattern with small inter-quartile range than the longer durations (larger range between 75 and 25 percentile values). The 25 percentile rainfall amounts for the storm durations less than $2 \mathrm{~h}$ were close to the median compared to the difference between the 75 percentile rainfall value and the median rainfall. However, for the storm durations longer than $4 \mathrm{~h}$, the median rainfall value tends to shift toward the 75 percentile value, except for the daily rainfall value for which case the median value again moves closer to the 25 percentile value (Fig. 1). Interestingly, there is not much variability of median rainfall for 4-9-h durations, which could be due the fact that most of the shortduration heavy rainfall is due to single convective storm event, whereas the long-duration rainfalls might be due to multiple thunderstorms or due to several bursts of rainfall during the monsoon seasons.

\section{Regional rainfall relation}

The mean annual maximum rainfall of various durations was plotted using Grapher to study the relation with respect to storm duration. However, no distinct pattern could be identified based on the spatial data, which could lead to useful regionalization. As such, envelop curves of the rainfall coefficients (ratio to daily rainfall value) are proposed for the whole Klang Valley, instead of dividing the area into several irregular regions. Envelop curves of the best fit relationships for upper envelop ( 90 percentile), median envelop (50 percentile) and lower envelop (10 percentile) were developed for the ratio of short-duration rainfall to daily ( $24 \mathrm{~h}$ ) rainfall values for the Klang Valley and the areas within Selangor and Federal Territories (Kuala Lumpur and Putrajaya).

Figure 2 shows that the mean annual maximum daily rainfall amount was the highest in the city centers of the Federal Territory of Kuala Lumpur and Kuala Kubu Baru areas (about $120 \mathrm{~mm}$ ). For the other neighboring areas of these city centers and towns, the mean annual maximum daily rainfall was about $110 \mathrm{~mm}$. The areas along the middle reaches of the west coast (Fig. 2) experienced mean annual maximum daily rainfall of about $100 \mathrm{~mm}$. Ratios of the mean annual maximum short-duration rainfall values to the mean of the annual maximum daily rainfall of each station were calculated (Table 2) to formulate the information (Table 3, Eq. 2-7 and Fig. 5) required to calculate the short-duration design rainfall value of any desired duration less than $24 \mathrm{~h}$.

Figure 3 shows that difference between the median SDRC values and maximum SDRC values was high for storm durations up to $2 \mathrm{~h}$. These differences were less for the storm durations longer than $2 \mathrm{~h}$. Such relation was opposite in the case of the median and lowest SDRC values for the study area. Isohyetal maps of the hourly rainfall are shown in Fig. 4, which shows the spatial distribution of the ratios of 1 -h rainfall to the daily ( $24 \mathrm{~h}$ ) rainfall value.

No visual distinct pattern for the spatial distribution of the rainfall ratios could be observed for Klang Valley. As such, instead of breaking into several regions, three envelope curves are proposed to estimate the short-duration rainfall values when the historical daily rainfall values are available in the Klang Valley.

\section{Short-duration rainfall design charts}

Design charts for short-duration rainfall coefficients (SDRC), which are basically ratio to the mean annual maximum daily rainfall values, for the Klang Valley are developed as shown in Fig. 5. The SDRC values are also given in Table 3, which can be multiplied with the mean annual maximum daily rainfall values of any rainfall station to estimate the mean annual maximum short-duration rainfall values.

\section{Short-duration rainfall estimation equations}

Table 3 or the design charts and equations in Fig. 5 can be used to estimate the short-duration rainfall of any duration less than $24 \mathrm{~h}$, by using the following equations:

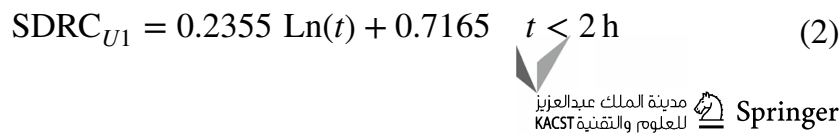




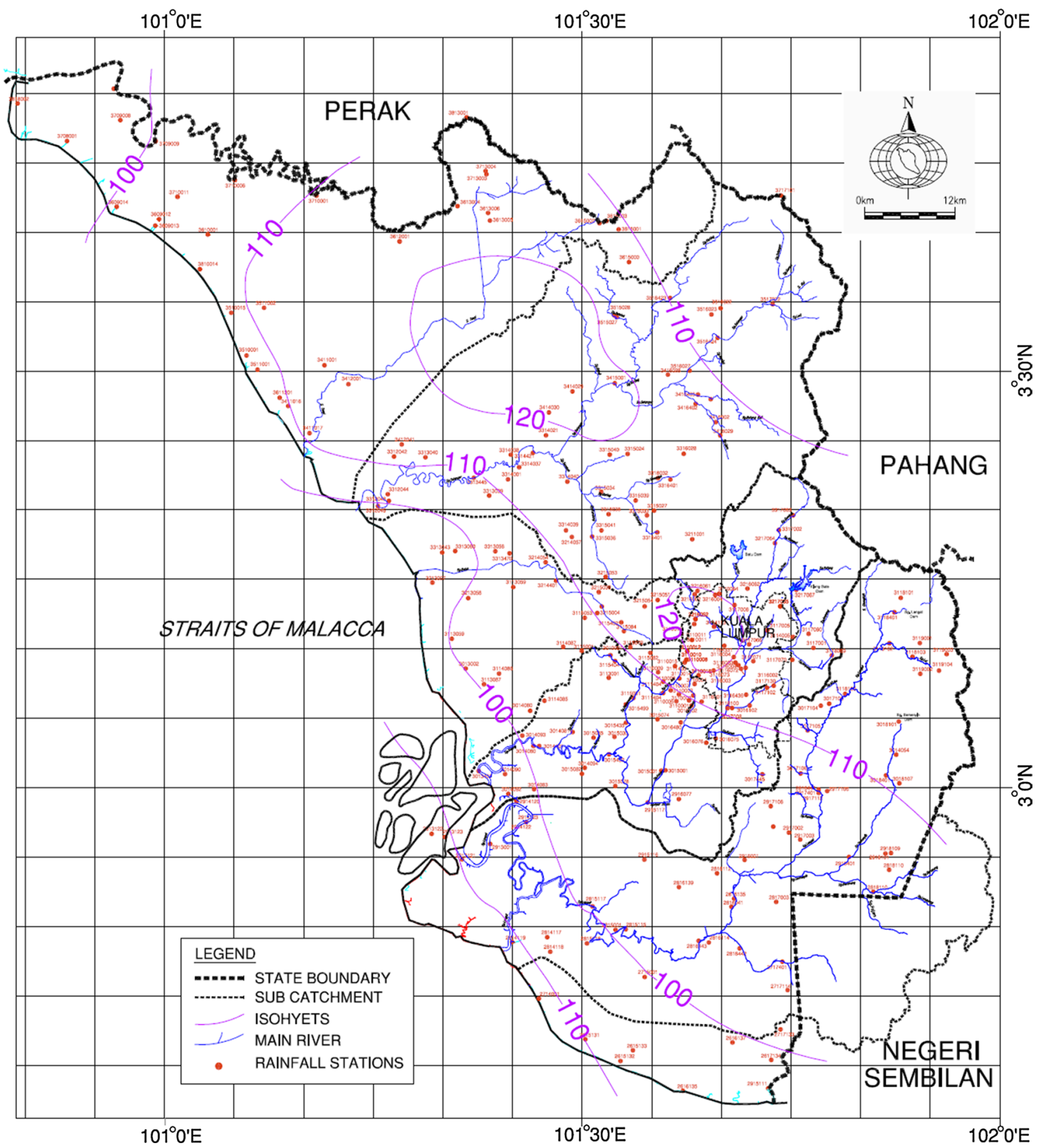

Fig. 2 Isohyets of mean annual daily ( $24 \mathrm{~h}$ ) maximum rainfall in Klang Valley

$$
\begin{array}{ll}
\mathrm{SDRC}_{\mathrm{U} 2}=0.0550 \operatorname{Ln}(t)+0.8356 & t>2 \mathrm{~h} \\
\mathrm{SDRC}_{\mathrm{M} 1}=0.2167 \operatorname{Ln}(t)+0.6292 & t<2 \mathrm{~h} \\
\mathrm{SDRC}_{\mathrm{M} 2}=0.0852 \operatorname{Ln}(t)+0.7105 & t>2 \mathrm{~h} \\
\mathrm{SDRC}_{\mathrm{L} 1}=0.2134 \operatorname{Ln}(t)+0.5520 & t<2 \mathrm{~h} \\
\mathrm{SDRC}_{\mathrm{L} 2}=0.1046 \operatorname{Ln}(t)+0.6093 & t>2 \mathrm{~h}
\end{array}
$$

where $t$ is the storm duration in hour. The subscript $\mathrm{U}, \mathrm{M}$ and $\mathrm{L}$ are the subscripts for upper, median and lower envelops.
Two sets of equations are given for each envelop curve. One equation (with subscript ${ }_{1}$ ) is for the storm duration less than $2 \mathrm{~h}$ and the other (with subscript ${ }_{2}$ ) is for equal to and more than $2 \mathrm{~h}$. Now, the mean annual maximum short-duration rainfall (SDR) can be estimated by the following equation:

$\mathrm{SDR}=\mathrm{SDRC} \times$ MAMDR

where MAMDR is the mean annual maximum daily rainfall (mm). 
Table 2 Statistical summary of the short-duration rainfall ratios to the daily rainfall

\begin{tabular}{|c|c|c|c|c|c|c|c|c|c|c|c|c|}
\hline \multirow[t]{2}{*}{ Parameter } & \multicolumn{12}{|c|}{ Ratios of short-duration rainfall to the daily rainfall for the duration of } \\
\hline & $15 \min$ & $30 \mathrm{~min}$ & $45 \mathrm{~min}$ & $1 \mathrm{~h}$ & $2 \mathrm{~h}$ & $3 \mathrm{~h}$ & $4 \mathrm{~h}$ & $5 \mathrm{~h}$ & $6 \mathrm{~h}$ & $9 \mathrm{~h}$ & $12 \mathrm{~h}$ & $18 \mathrm{~h}$ \\
\hline Minimum & 0.211 & 0.341 & 0.403 & 0.467 & 0.557 & 0.566 & 0.577 & 0.603 & 0.635 & 0.693 & 0.748 & 0.751 \\
\hline 10 percentile & 0.250 & 0.402 & 0.494 & 0.570 & 0.687 & 0.736 & 0.757 & 0.784 & 0.794 & 0.820 & 0.840 & 0.878 \\
\hline Median & 0.324 & 0.471 & 0.574 & 0.649 & 0.765 & 0.809 & 0.835 & 0.852 & 0.864 & 0.890 & 0.910 & 0.945 \\
\hline Mean & 0.319 & 0.483 & 0.582 & 0.648 & 0.765 & 0.809 & 0.835 & 0.855 & 0.867 & 0.889 & 0.905 & 0.936 \\
\hline 90 percentile & 0.365 & 0.562 & 0.673 & 0.738 & 0.849 & 0.894 & 0.923 & 0.943 & 0.946 & 0.957 & 0.973 & 0.988 \\
\hline Maximum & 0.543 & 0.674 & 0.752 & 0.821 & 0.934 & 0.941 & 0.952 & 0.978 & 0.975 & 0.996 & 0.998 & 0.999 \\
\hline Skewness & 0.64 & 0.28 & 0.13 & 0.07 & -0.46 & -0.87 & -0.97 & -1.00 & -0.97 & -0.80 & -0.69 & -1.25 \\
\hline SD & 0.05 & 0.07 & 0.07 & 0.07 & 0.07 & 0.07 & 0.07 & 0.07 & 0.07 & 0.06 & 0.05 & 0.05 \\
\hline
\end{tabular}

Table 3 SDRC values for the Klang Valley

\begin{tabular}{lllllllllllll}
\hline Envelop curve & \multicolumn{1}{l}{ SDRC values for the duration $(\mathrm{h})$ of } \\
\cline { 2 - 13 } & $15 \mathrm{~min}$ & $30 \mathrm{~min}$ & $45 \mathrm{~min}$ & $1 \mathrm{~h}$ & $2 \mathrm{~h}$ & $3 \mathrm{~h}$ & $4 \mathrm{~h}$ & $5 \mathrm{~h}$ & $6 \mathrm{~h}$ & $9 \mathrm{~h}$ & $12 \mathrm{~h}$ & $18 \mathrm{~h}$ \\
\hline Upper (90 percentile) & 0.365 & 0.562 & 0.673 & 0.738 & 0.849 & 0.894 & 0.923 & 0.943 & 0.946 & 0.957 & 0.973 & 0.988 \\
Median (50 percentile) & 0.324 & 0.471 & 0.574 & 0.649 & 0.765 & 0.809 & 0.835 & 0.852 & 0.864 & 0.890 & 0.910 & 0.945 \\
Lower (10 percentile) & 0.250 & 0.402 & 0.494 & 0.570 & 0.687 & 0.736 & 0.757 & 0.784 & 0.794 & 0.820 & 0.840 & 0.878 \\
\hline
\end{tabular}

Fig. 3 Variation of short-duration rainfall coefficient (SDRC) to the daily rainfall

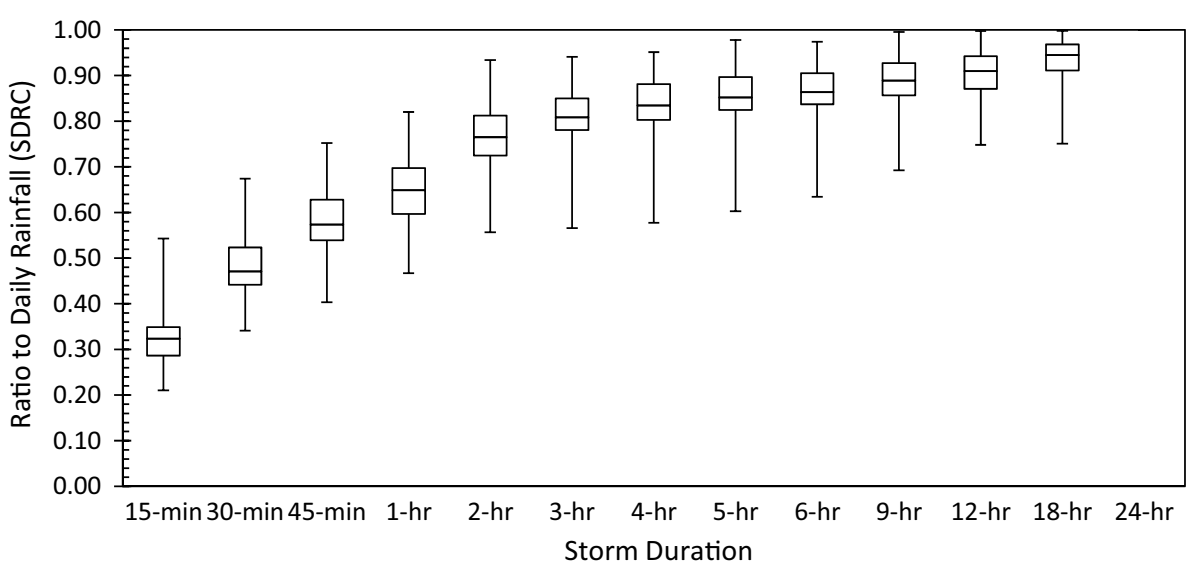

\section{Application procedure}

The application procedure of the design charts is very straight forward, which is given as follows:

1. Identify the location of the study area;

2. Find the mean annual maximum daily rainfall (MAMDR) value of the study area (from the nearby rainfall station, or relevant DID publications such as HP or WRP, report);

3. Determine the duration of rainfall (less than $24 \mathrm{~h}$ ) for which the rainfall depth (in $\mathrm{mm}$ ) to be calculated;

4. Depending on the storm duration (less than or more than $2 \mathrm{~h}$ ), calculate the median short-duration rainfall coefficient $\left(\mathrm{SDRC}_{\mathrm{M}}\right)$ value using Eqs. 4 or 5.
5. Calculate the short-duration rainfall (SDR) value using Eq. 8.

6. Repeat the procedure to calculate the possible upper and lower limits of the estimated short-duration rainfall values for any checking or verification purpose.

7. Verify the SDRC values calculated using the equations with the values shown in Fig. 5, before finalizing estimated short-duration rainfall values.

Although the short-duration rainfall estimation equations and charts (presented in this report) were developed based on the MAMDR records, the procedure can be used for "quick estimation" of any short-duration rainfall. For instance, if the "daily rainfall" of 5-year return period (or any other return period) is known for any location, this procedure can be 


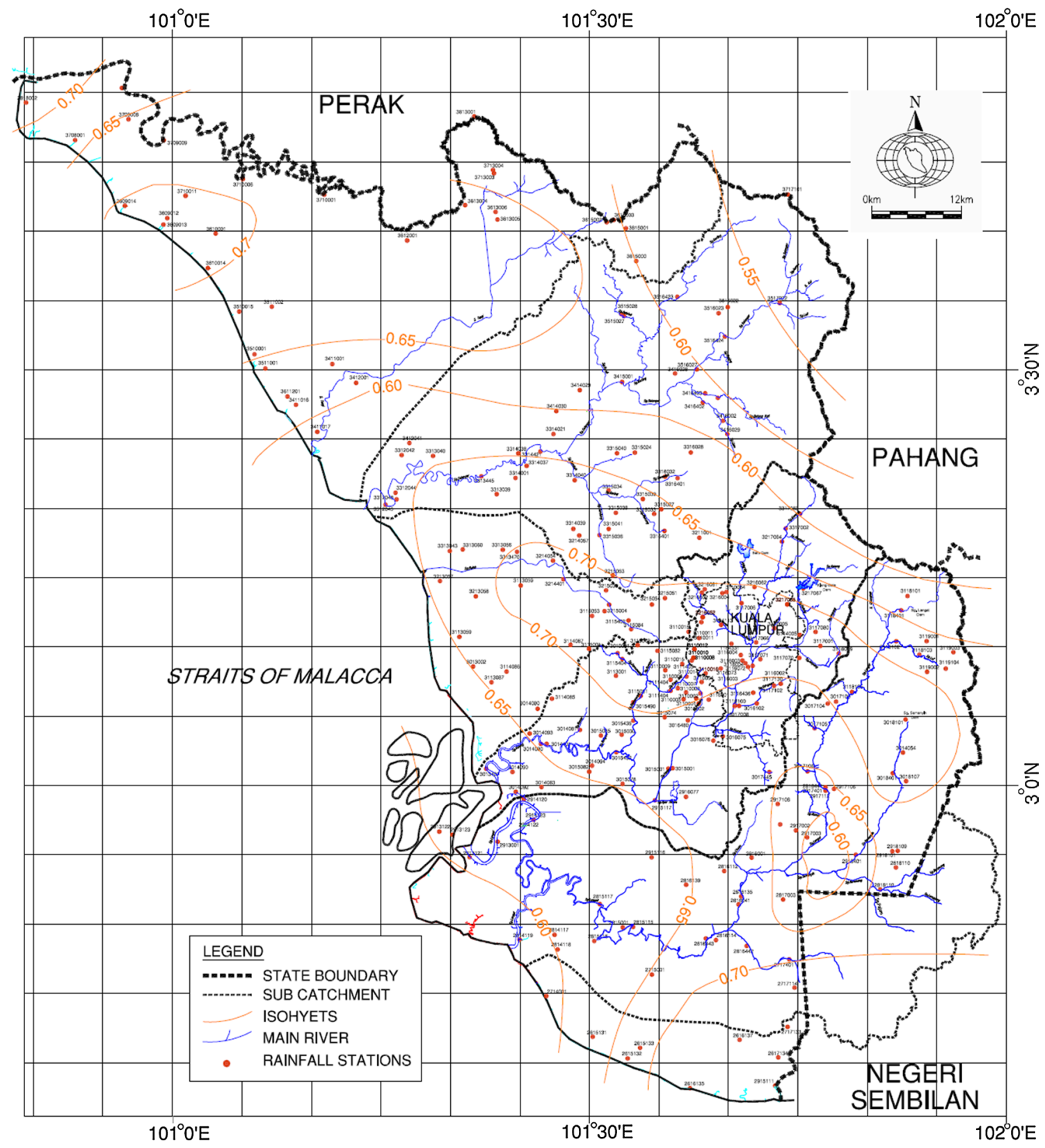

Fig. 4 Isohyetal map of the 1-hr rainfall ratio (SDRC) to the daily rainfall value

used for "quick estimation" of any short-duration rainfall of 5-year return period (or relevant condition) for planning and design purpose.

\section{Conclusions}

Short-duration rainfall is critical for the small catchments and urban drainage systems. There is always a shortage of short-duration rainfall data as it requires automatic rain gauges to record such data. On the contrary, daily rainfall values are generally available due to the use of cheap manual instruments. The authors could not find any reliable methods to estimate short-duration rainfall data based on the daily rainfall values. As such, long-term data of the rainfall stations in Klang Valley area were used to develop very good statistically acceptable $\left(R^{2}>0.90\right)$ relation between shortduration rainfall and daily rainfall data. Very unique trend was observed which might be used to estimate short-duration rainfall based on the daily rainfall data of the manual rain gauging stations. Use of such relations may help the relevant authorities overcome the demands of installing more rain gauge stations in the country, including the expensive automatic data logging rainfall measuring instruments. 
Fig. 5 Charts and regression equations for short-duration rainfall coefficients (SDRC)

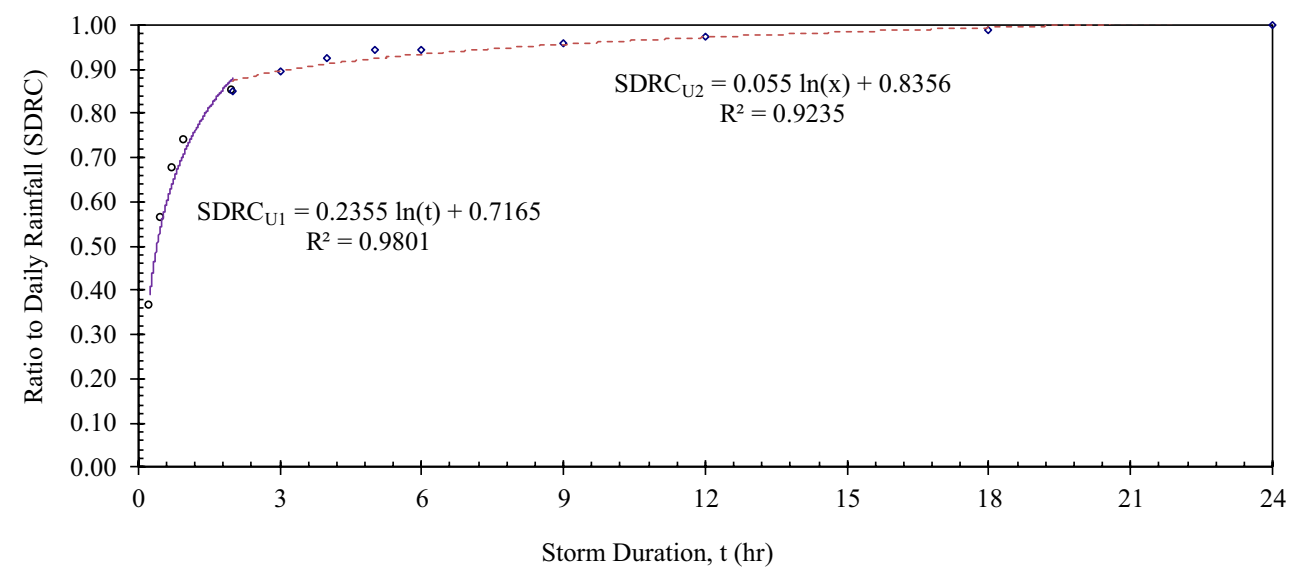

(a) Upper Envelop Curve

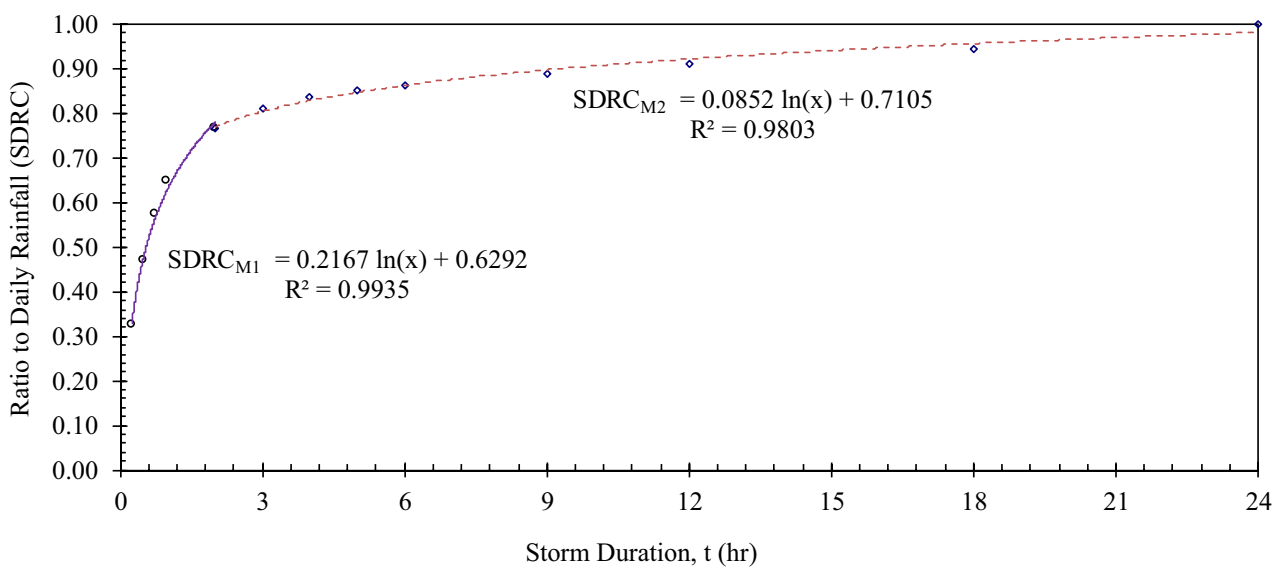

(b) Median Envelop Curve

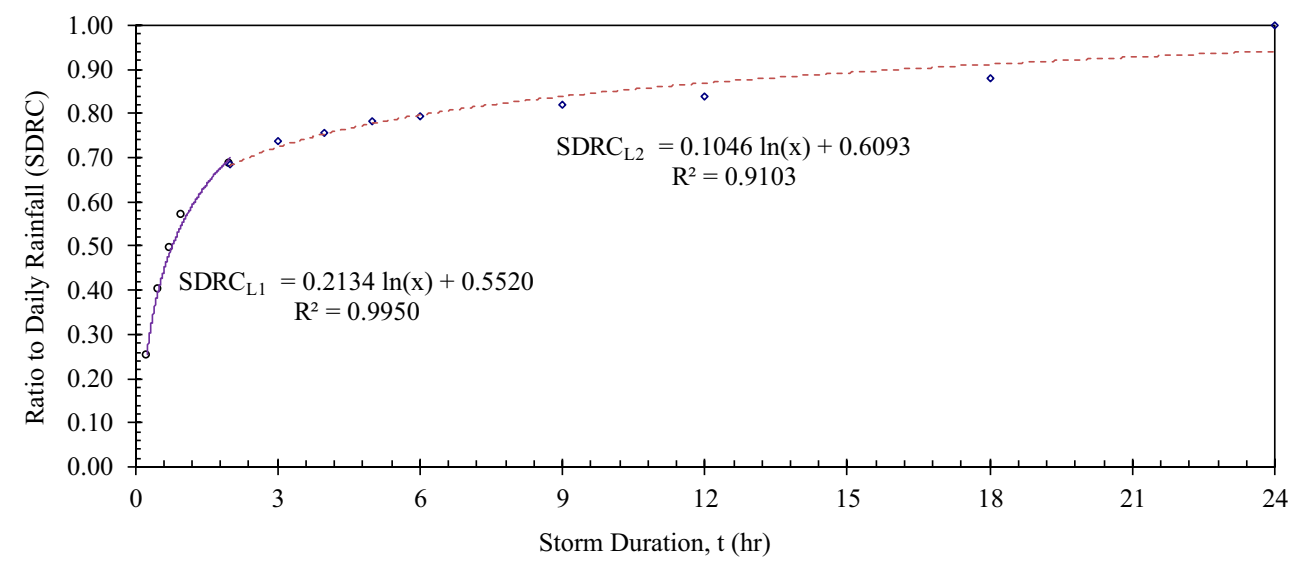

(c) Lower Envelop Curve
Additional studies can be conducted in other parts of the globe to validate the existence of similar relationship between the short and daily rainfall events. Establishment of such correlation on global scale would not only help reduce the necessity of expensive automatic data logging rainfall measuring devices but also help make use of the available daily rainfall data to estimate the short-duration rainfall necessary for various purposes.
Acknowledgements The financial support from the Department of Irrigation and Drainage (DID) Malaysia (Ref. No. JPS: PPS.11/12/1 $\mathrm{RB}$ ) to conduct this study is greatly acknowledged. Data provided by the MMD are also highly appreciated.

Open Access This article is distributed under the terms of the Creative Commons Attribution 4.0 International License (http://creativeco mmons.org/licenses/by/4.0/), which permits unrestricted use, distribution, and reproduction in any medium, provided you give appropriate 
credit to the original author(s) and the source, provide a link to the Creative Commons license, and indicate if changes were made.

\section{References}

Allan RP, Soden BJ (2008) Atmospheric warming and the amplification of precipitation extremes. Science 321(5895):1481-1484

Cheng L, AghaKouchak A (2014) Nonstationary precipitation intensity-duration-frequency curves for infrastructure design in a changing climate. Sci Rep 4:7093

Chowdhury R et al (2007) Short duration rainfall estimation of Sylhet: IMD and USWB method. J Indian Waterworks Assoc 39(4):285

Cunnane C (1989) Statistical distributions for flood frequency analysis. Operational hydrology report (WMO)

Desa M, Rakhecha P (2004) Characteristics of short-duration extreme rainfalls in Selangor, Malaysia. Weather 59(3):63-66

Easterling DR, Meehl GA, Parmesan C, Changnon SA, Karl TR, Mearns LO (2000) Climate extremes: observations, modeling, and impacts. Science 289(5487):2068-2074

Einfalt T, Gerlach N, Podlasly C, Demuth N (2008) Rainfall and climate data quality control. In: 11th international conference on urban drainage, Edinburgh, Scotland, UK

El-Sayed EAH (2011) Generation of rainfall intensity duration frequency curves for ungauged sites. Nile Basin Water Sci Eng J 4(1):112-124

Garcia-Bartual R, Schneider M (2001) Estimating maximum expected short-duration rainfall intensities from extreme convective storms. Phys Chem Earth Part B 26(9):675-681

Goswami BN, Venugopal V, Sengupta D, Madhusoodanan MS, Xavier PK (2006) Increasing trend of extreme rain events over India in a warming environment. Science 314(5804):1442-1445

Haddad K et al (2011) Design rainfall estimation for short storm durations using L-moments and generalised least squares regressionapplication to Australian data. Int J Water Res Arid Environ $1: 210-218$

Hamada A, Takayabu YN, Liu C, Zipser EJ (2015) Weak linkage between the heaviest rainfall and tallest storms. Nat Commun 6:6213

Hamzah EAH (2005) Regionalisation frequency analysis of short duration rainfall for Peninsular Malaysia. Universiti Teknologi MARA, Shah Alam

Hong B, Gasse F, Uchida M, Hong Y, Leng X, Shibata Y, Wang Y (2014) Increasing summer rainfall in arid eastern-Central Asia over the past 8500 years. Sci Rep 4:5279

Hosking JRM, Wallis JR (2005) Regional frequency analysis: an approach based on L-moments. Cambridge University Press, Cambridge

Kumar P (2013) Hydrology: seasonal rain changes. Nat Clim Change 3(9):783-784

Lettenmaier D (1985). Regionalisation in flood frequency analysis-Is it the answer. US-China Bilateral symposium on the analysis of extraordinary flood events. Nanjing, China

Logah F et al (2013) Developing short duration rainfall intensity frequency curves for Accra in Ghana. Int J Latest Res Eng Comput $1: 67-73$
Min SK, Zhang X, Zwiers FW, Hegerl GC (2011) Human contribution to more-intense precipitation extremes. Nature 470(7334):378-381

Mudenda OS (2007) Spatial analysis and quality management of rainfall data at the Zambia meteorological department. In: 5th international symposium spatial data quality 200 . ISPRS archivesvolume XXXVI-2/C43

Nguyen V et al (1998) Regional estimation of short duration rainfall extremes. Water Sci Technol 37(11):15-19

NIWA (2017) Tideda analysis and database software. National Institute of Water and Atmospheric Research-NIWA, New Zealand. https ://teamwork.niwa.co.nz/download/attachments/4456778/Tided a_Brochure.pdf?. Accessed on 10 March 2017

NOAA (2017) National Oceanic and Atmospheric AdministrationNOAA, the USA. http://www.cpc.ncep.noaa.gov/research_paper s/ncep_cpc_atlas/7/atlas_7.html. Accessed 10 March 2017

Okonkwo GI, Mbajiorgu CC (2010) Rainfall intensity-duration-frequency analysis for Southeastern Nigeria. Agric Eng Int CIGR J 12(1):22-30

Potter KW (1987) Research on flood frequency analysis: 1983-1986. Rev Geophys 25(2):113-118

Rashid M et al (2012) Modeling of short duration rainfall intensity duration frequency (SDRIDF) equation for Sylhet City in Bangladesh. ARPN J Sci Technol 2(2):92-95

Reich B (1961) Short duration rainfall intensity in South Africa. SA J Agric Sci 4(4):589-614

Reich BM (1963) Short-duration rainfall-intensity estimates and other design aids for regions of sparse data. J Hydrol 1(1):3-28

Smithers J (1993) The effect on design rainfall estimates of errors in the digitised rainfall database. In: Proceedings of the Sixth South African National hydrological symposium. Department of Agricultural Engineering, University of Natal. Pietermaritzburg, RSA

Smithers JC, Schulze R (2000) Development and evaluation of techniques for estimating short duration design rainfall in South Africa. Water Research Commission, Pretoria

Smithers J, Schulze R (2001) A methodology for the estimation of short duration design storms in South Africa using a regional approach based on L-moments. J Hydrol 241(1):42-52

Syafrina AH, Zalina MD, Juneng L (2015) Historical trend of hourly extreme rainfall in Peninsular Malaysia. Theoret Appl Climatol 120(1-2):259-285

Wang J (1987) Study of design storms in China. J Hydrol 96(1):279-291

Yu P-S et al (2004) Regional rainfall intensity formulas based on scaling property of rainfall. J Hydrol 295(1):108-123

Zeng N, Neelin JD, Lau KM, Tucker CJ (1999) Enhancement of interdecadal climate variability in the Sahel by vegetation interaction. Science 286(5444):1537-1540

Publisher's Note Springer Nature remains neutral with regard to jurisdictional claims in published maps and institutional affiliations. 